\title{
Quality of life in men diagnosed with anogenital warts*
}

\author{
Caio Cavassan de Camargo ${ }^{1}$ \\ Helio Amante Miot ${ }^{2}$
}

Maria Paula Barbieri D’Elia²

DOI: http:/ / dx.doi.org/10.1590/abd1806-4841.20175282

\begin{abstract}
Anogenital warts are a worldwide public health problem. They consist of epithelial proliferations caused by HPV, whose transmission occurs mainly through sexual intercourse. In this study, we evaluated their impact on the quality of life of adult males. We interviewed 88 men in an outpatient clinic for sexually transmitted diseases at a Brazilian public institution, using the DLQI-BRA questionnaire. Most patients (81\%) presented mild or no impairment of quality of life. The main dimensions affected were sex life, symptoms, and embarrassment. The low impact on quality of life may well justify the delay in seeking medical treatment, favoring the spread of the disease.
\end{abstract}

Keywords: Condylomata acuminata; Male; Male urogenital diseases; Men's health; Papillomavirus Infections; Quality of life; Sexually transmitted diseases, viral

Anogenital warts (AGWs) are sexually transmitted diseases (STDs) that are quite common in specialized outpatient clinics $(30 \%$ to $40 \%$ ). Their incidence has been increasing, especially among individuals with more than three partners during one's lifetime and among those who begin their sexual life at an early age. In Brazil, there is no official register of the incidence of AGWs; however, estimations from the World Health Organization (WHO) are of up to 685,400 cases/year. ${ }^{1,2}$

AGWs are epithelial proliferations caused by a wide range of HPV genotypes - primarily 6 and 11, which are more adapted to the genital topography and of low carcinogenic risk. ${ }^{1}$

In adults, the main means of transmission of AGWs is through sexual intercourse. It is estimated that subclinical lesions are responsible for more than $90 \%$ of the contagions. However, it is the presence of AGWs, clinically represented by vegetative papules, of an irregular surface and normochromic, that lead the patient to seek medical care. ${ }^{3}$

There are few investigations on the impact of AGWs in men's quality of life (QL). The understanding of aspects that bring about limitations upon one's everyday life may well contribute to the development of campaigns aimed at primary prevention, early diagnosis, and early treatment.

The Dermatology Life Quality Index (DLQI) was the first general psychometric instrument to evaluate QL in dermatology. Its total score is calculated by the sum of ten evaluated items and is interpreted as follows: no impairment of QL (0 to 1), mild impairment (2 to 5), moderate impairment (6 to 10), severe impairment (11 to 20), or very severe impairment ( 21 to 30$){ }^{4}$

To evaluate the impact of AGWs on QL, a questionnaire geared towards men of 14 years of age or older and who have been diagnosed with AGWs were carried out during their doctor's appointments at a public health referral service (Unesp, Botucatu, Brazil), between February 2011 and June 2015. Socio-behavioral, demographic, and disease aspects were evaluated. The DLQI-BRA questionnaire (validated to the Portuguese language) was also applied. ${ }^{4}$ The study was approved by the institution's ethics committee (Protocol number - CAAE: 47321515.3.0000.5411).

The categorical variables were described by absolute and percentage frequencies, as well as by quantitative frequencies, by averages and standard deviations, or by medians and quartiles (p25-p75). Normality was evaluated using the Kolmogorov-Smirnov test. Correlations among the quantitative variables were estimated by the Spearman coefficient $\left(\mathrm{r}_{\mathrm{s}}\right)$. DLQI total scores were compared among the subgroups by the Mann-Whitney test or by Jonckheere-Terpstra test. The internal consistency of the questionnaire was estimated by the Cronbach alpha coefficient. The results were analyzed in the IBM-SPSS 21 program, and the p-values of less than or equal to 0.05 were considered significant.

Received on 23.10.2015

Approved by the Advisory Board and accepted for publication on 16.05.2016

* Work conducted at the Botucatu School of Medicine, Universidade Estadual Paulista “Júlio de Mesquita Filho" (FMB-Unesp) - Botucatu (SP) Brazil. Financial support: none.

Conflict of interest: none.

1 Department of Tropical Disesases and Imagery Diagnostics, Botucatu School of Medicine, Universidade Estadual Paulista “Júlio de Mesquita Filho" (FMBUnesp) - Botucatu (SP) Brazil.

2 Department of Dermatology and Radiotherapy, Botucatu School of Medicine, Universidade Estadual Paulista "Júlio de Mesquita Filho" (FMB-Unesp) Botucatu (SP) Brazil. 


\begin{tabular}{|c|c|}
\hline \multirow[t]{2}{*}{ Variables } & \multirow{2}{*}{$\begin{array}{l}\text { Data } \\
\text { N }(\%)\end{array}$} \\
\hline & \\
\hline Age (years) - average (SD) & $39(14,5)$ \\
\hline $\begin{array}{l}\text { Age upon onset of the disease (years) - } \\
\text { average (SD) }\end{array}$ & $36,2(13,3)$ \\
\hline Time of disease (months) - median (p25-p75) & 12 (6 and 36$)$ \\
\hline HIV Positive & $20(23)$ \\
\hline $\begin{array}{l}\text { Living with the partner in the same } \\
\text { household }\end{array}$ & $38(43)$ \\
\hline Homosexual relationship & $9(10)$ \\
\hline \multicolumn{2}{|l|}{ Education } \\
\hline None & $3(3)$ \\
\hline Elementary & $35(40)$ \\
\hline High School & $33(38)$ \\
\hline University & $17(19)$ \\
\hline \multicolumn{2}{|l|}{ Number of partners/year } \\
\hline$\leq 2$ & $59(67)$ \\
\hline $3-5$ & $12(14)$ \\
\hline$>5$ & 17 (19) \\
\hline \multicolumn{2}{|l|}{ Topography of the lesions } \\
\hline Shaft & $36(41)$ \\
\hline Foreskin & $29(33)$ \\
\hline Glans & $21(24)$ \\
\hline Scrotum & $8(9)$ \\
\hline Others (perineum, perianal region) & $33(38)$ \\
\hline \multicolumn{2}{|l|}{ Therapeutic option } \\
\hline Cryosurgery & $63(72)$ \\
\hline Electrosurgery & $24(27)$ \\
\hline Trichloroacetic Acid & $10(11)$ \\
\hline Podophyllotoxin & $7(8)$ \\
\hline Other & $10(11)$ \\
\hline Total - median DLQI (p25-p75) & $2(0$ e 5$)$ \\
\hline \multicolumn{2}{|l|}{ Categorized DLQI } \\
\hline No impairment & $40(45)$ \\
\hline With mild impairment & $31(35)$ \\
\hline With moderate impairment & $13(15)$ \\
\hline With severe impairment & $3(3)$ \\
\hline With very severe impairment & $1(1)$ \\
\hline
\end{tabular}

SD: standard deviation

p25-p75: percentile 25-percentile 75

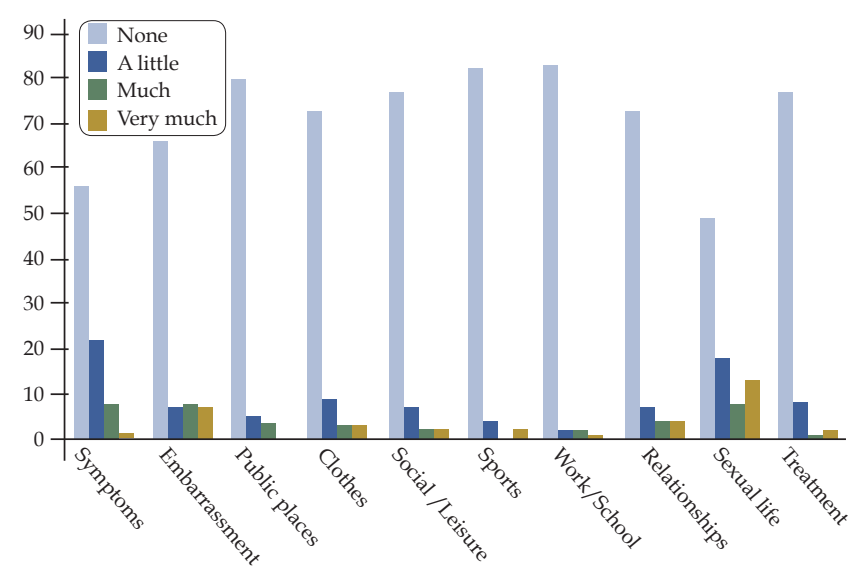

FIGURE 1: Frequency of responses to the DLQI questionnaire according to the evaluated item (question)
We evaluated 88 patients, whose main clinical and demographic data can be found in table 1. Prominent information included: individuals at a productive working age (under 60), lesions found mainly in the shaft $(41 \%)$ and foreskin (33\%), cryosurgery as the most commonly applied therapeutic option (72\%), and median time of living with the disease of one year.

The internal consistency of the questionnaire resulted in 0.73 (Cronbach alpha). The patients' total DLQI scores were predominately found between the "no impairment" and "with mild impairment" of QL (80\%) (Table 1). The highest scores were found among homosexuals [5 (4-7) vs $2(0-4), \mathrm{p}=0.01]$ as well as in perineal and perianal lesions [ $3(1-5)$ vs $1(0-3), p=0.03$ ]. The lowest scores were identified among those affected in the penis shaft $[1(0-3)$ vs 3 $(0-6), p<0.01$ ] and in those undergoing treatment with cryosurgery [1 (0-3) vs 4 (1-7), p < 0.01]. In addition, weak correlations were found with the time of treatment $\left(r_{s}=0.24 ; p=0.02\right)$ and with the number of partners $\left(r_{s}=0.23 ; p=0.03\right)$.

No association was identified between the DLQI and the presence of HIV, marital status, and education level $(p>0.1)$; there was also no correlation with age $\left(r_{s}=-0.09 ; p=0.40\right)$ and the time of disease $\left(r_{s}=0.07 ; p=0.50\right)$.

The most affected items were sexual life, symptoms, and embarrassment; however, in most questions, it was observed that up to two-thirds of the patients presented nothing/no relevance (Figure 1).

The study of AGWs in men illustrated a minimal impact on their QL. The most affected dimensions were the links to interpersonal relationships, symptoms, and embarrassment. In Brazil, other dermatoses provoke a higher DLQI score, such as autoimmune blistering diseases (16), chronic hives (14), leprosy (11), basal-cell carcinoma (9), acne (7), contact dermatitis (7), and vitiligo (4)..$^{5-7}$

Other researchers have also shown a discrete impact on QL caused by AGWs on different continents; however, no study has been conducted in Latin America nor has the DLQI been applied as an instrument. Social and psychological impacts, embarrassment, sexual limitations, and uncertainties related to therapies have also been reported..$^{8-10}$

The lack of AGW symptoms, even in cases with extensive lesions, allow for the patient to live a long time with the disease, which strengthens the transmission cycle and contagion, as demonstrated in our patients with a median of 12 months of disease. Additionally, AGWs and other STDs maximize the prevalence of HIV ${ }^{1}$ - this study demonstrated a high prevalence of HIV patients (23\%) - in relation to the general population.

The disease causes embarrassment and limitations to one's QL, especially when the genitals are exposed, such as during sexual intercourse, and even more when having sex with multiple partners. The population's education regarding the identification of discrete lesions and the confirmation that the partner can reject intimate contact with AGW patients can be used as a strategy in prevention campaigns, encouraging safe sex and the early treatment of lesions.

The therapeutic options for AGWs are, in most cases, of surgical nature, causing the need for care and pain/discomfort, especially for those who require many sessions. Such evidence suggests that the availability of treatments of less morbidity may well be im- 
portant in convincing the patients to seek early treatment and the interruption of the transmission chain. ${ }^{3}$

The most important limitation of this study is restricted to the exclusive representativeness of male public health's patients.
However, the large homogeneity of responses appropriately characterizes this population and strengthens the internal validity of the findings, though these cannot be extrapolated to other populations or other social realities.

\section{REFERENCES}

1. Fagundes LJ, Vieira EE Jr, Moysés AC, Lima FD, Morais FR, Vizinho NL. Sexually Transmitted Diseases in a specialized STD healthcare center: epidemiology and demographic profile from January 1999 to December 2009. An Bras Dermatol. 2013;88:523-9.

2. Aids.gov.br [Internet]. Ministério da Saúde. Departamento de DST, Aids e Hepatites Virais. Portal sobre aids, infecções sexualmente transmissíveis e hepatites virais. Dados de Pesquisa, DST no Brasil. 2010 [acesso 3 Set 2013]. Disponível em: http://www.aids.gov.br/pagina/dst-no-brasil.

3. Lopaschuk CC. New approach to managing genital warts. Can Fam Physician. 2013;59:731-6.

4. Zogbi H. Avaliação de qualidade de vida em pacientes com dermatoses: estudo de adaptação e validação do Dermatology Life Quality Index (DLQI) para uma amostra sul-brasileira [dissertação]. Porto Alegre (RS): Pontifícia Universidade Católica do Rio Grande do Sul; 2004.

5. Nunes DH, Fröde TS. Quality of life in Basal cell carcinoma patients in Brazil: a pilot cross sectional study. Dermatol Surg. 2013;39:620-6.

6. Silvares MR, Fortes MR, Miot HA. Quality of life in chronic urticaria: a survey at a public university outpatient clinic, Botucatu (Brazil). Rev Assoc Med Bras (1992). 2011;57:577-82.

7. Penha MÁ, Farat JG, Miot HA, Barraviera SR. Quality of life index in autoimmune bullous dermatosis patients. An Bras Dermatol. 2015;90:190-4.

8. Sénécal M, Brisson M, Maunsell E, Ferenczy A, Franco EL, Ratnam S, et al. Loss of quality of life associated with genital warts: baseline analyses from a prospective study. Sex Transm Infect. 2011;87:209-15.

9. Shi JF, Kang DJ, Qi SZ, Wu HY, Liu YC, Sun LJ, et al. Impact of genital warts on health related quality of life in men and women in mainland China: a multicenter hospital-based cross-sectional study. BMC Public Health. 2012;12:153.

10. Mortensen GL, Larsen HK. The quality of life of patients with genital warts: a qualitative study. BMC Public Health. 2010;10:113.

\section{MAILING ADDRESS: \\ Caio Camargo \\ Departamento de Dermatologia e Radioterapia Faculdade de Medicina de Botucatu - Unesp \\ Campus Universitário de Rubião Jr. \\ 18618-000 - Botucatu - SP \\ Brazil \\ E-mail:caiocavassan@yahoo.com.br}

How to cite this article: Camargo CC, D'Elia MPB, Miot HA. Quality of life in men affected by anogenital warts. An Bras Dermatol. 2017;92(3):427-9. 